\title{
ENFERMAGEM E HISTÓRIA DA ENFERMAGEM: ASPECTOS EPISTEMOLÓGICOS DESTACADOS NA CONSTRUÇÃO DO CONHECIMENTO PROFISSIONAL
}

\author{
Nursing and Nursing History: Epistemological Aspects Detached \\ in the Professional Knowledge Construction \\ Enfermería e Historia de la Enfermería: Aspectos Epistemológicos Destacados \\ en la Construcción del Conocimiento Profesional
}

Vilma de Carvalho

\begin{abstract}
Resumo
Trata de discutir o tema designado como "A Construção do Saber de História da Enfermagem" com dois objetivos: 1. contribuir na ampliação do espaço dos pesquisadores da enfermagem justificando seus direitos em relação aos objetos de estudo ligados às disciplinas de sua formação profissional - Enfermagem e História da Enfermagem; e 2. ressaltar conceitos para uma epistemologia da enfermagem considerando aspectos da construção do conhecimento potenciais para reduzir dificuldades nas pesquisas da enfermagem, em especial no interesse da história da enfermagem brasileira. A abordagem parte da atitude intelectual face ao assunto e é colocada segundo uma postura crítica coerente com conjeturas e reflexões acerca de aspectos epistemológicos destacados na construção do conhecimento profissional, com mais pertinência ao pensar sobre Enfermagem - seu saber e sua história. As considerações visam a idéia representada pela questão de conhecimentos em construção a meio caminho entre subjetividade e objetividade - aspectos epistemológicos desses conhecimentos, e como sucedem no campo epistêmico. A Enfermagem e a História da Enfermagem são focalizadas como um conjunto de elementos relativos à prática social da profissão e outros radicados nas determinações históricas. A autora trata o assunto com base em conceitos epistemológicos (Canguilhem e Barchelard) relativamente ao que se deve compreender por "história das ciências" e numa perspectiva do que se possa compreender por "a atualidade da história das ciências".
\end{abstract}

Palavras-chave: Enfermagem. História da Enfermagem. Formação de Conceito. Epistemologia.

\begin{abstract}
It treats to argue the designed theme as "the Construction of the History of the Nursing Know " with two objectives: 1. to contribute in the magnifying of the space of the researchers of the nursing justifying its rights related to the objects of study linked to the discipline of professional formation - Nursing and History of the Nursing; and 2, to stand out concepts for a epistemology of the nursing considering aspects of the construction of the knowledge potentials to reduce difficulties in the research of nursing, specially in the interest of the history of the Brazilian nursing. The approach come from the intellectual attitude face to the subject and is placed according to a coherent critical position with conjectures and reflections concerning the epistemological aspects detached in the construction of the professional knowledge, with more relevancies on the thinking about Nursing - its known and its history. The considerations aim at the idea represented by the question of knowledge in construction in the half way between subjectivity and objectivity - epistemological aspects of these knowledge, and as they occur in the epistemic field. The Nursing and the History of the Nursing are focused as a set of elements related to social practice of the profession and others consolidated in the historical determination. The author treats the theme on the basis of epistemological concepts (Canguilhem and Barchelard) relatively to that it must be understood as "history of sciences" and in a perspective of what can be understood as "the present time of the history of sciences".
\end{abstract}

\section{Keywords:}

Nursing. History of Nursing. Concept Formation. Knowledge.

\section{Resumen}

Tratase de discutir el tema designado como "la Construcción del Saber de la Historia de la Enfermería" con dos objetivos: 1. contribuir en la ampliación del espacio de los investigadores de enfermería justificando sus derechos en relación al objeto de estudio unidos a los cursos de su formación profesional - Enfermería e Historia de la Enfermería; y 2. resaltar conceptos para una epistemología de la enfermería considerando aspectos potenciales en la construcción del conocimiento para reducir dificultades en las investigaciones da enfermería, en especial en el interés de la historia de la enfermería brasileña. El abordaje parte de la actitud intelectual frente al asunto y es colocada siguiendo una postura crítica, coherente con conjeturas y reflexiones acerca de aspectos epistemológicos destacados en la construcción del conocimiento profesional, con mas pertinencia al pensar sobre Enfermería - su saber y su historia. Las consideraciones visan la idea representada por el problema de conocimientos en construcciónmedio camino entre subjetividad y objetividad - aspectos epistemológicos de esos conocimientos y como suceden en el campo epistémico. La Enfermería y la Historia de la Enfermería son enfocados como un conjunto de elementos relativos a la práctica social de la profesión y otros radicados en las determinaciones históricas. La autora trata el asunto con base en conceptos epistemológicos (Canguilhem y Barchelard) relativamente a lo que se debe comprender por "historia de las ciencias" y en una perspectiva de lo que se pueda comprender por "la actualidad de la historia de las ciencias".

Palabras clave:

Enfermería. Historia de la Enfermería. Formación de Concepto. Conocimiento. 


\section{ATITUDE INTELECTUAL E OBJ ETIVOS FRENTE AO TEMA}

Devo confessar, antes de tudo, que não me dedico especificamente, ao ensino de História da Enfermagem. Então, alguns esclarecimentos se impõem. Em verdade, sou enfermeira formada há mais de cinqüenta anos e licenciada em filosofia há mais de quarenta. 0 que sei sobre o tema designado como "A Construção do Saber de História da Enfermagem"a é pouco. Mas aceitei discutir o assunto, com o objetivo principal de contribuir para ampliar o espaço da posição dos pesquisadores da Enfermagem justificando seus direitos em relação a objetos de estudo pertinentes às disciplinas de sua formação profissional, como Enfermagem e História da Enfermagem. Com base em considerações filosóficas, pretendo alcançar também, o objetivo de ressaltar conceitos para uma epistemologia da enfermagem ${ }^{b}$, dentre os quais alguns condizentes com aspectos significativos na construção do conhecimento, potenciais para favorecer uma discussão para reduzir dificuldades nas pesquisas, mormente no interesse de História da Enfermagem Brasileira.

Para me ater aos objetivos definidos, cabe esclarecer que não disponho dos resultados de uma pesquisa, supostamente, já realizada. Por isso, não tratarei, especificamente, de métodos de pesquisa e nem de produtos intelectuais aliados à construção do conhecimento. Outros pesquisadores de História da Enfermagem podem demonstrar isto com propriedade. Minha atitude intelectual face ao tema é crítica e formalmente coerente com conjeturas e reflexões desenvolvidas nas contingências da vida profissional, ao longo de experiências de orientar alunos e de trocar idéias com parceiros de pesquisa. Por isso, tratarei apenas de aspectos epistemológicos destacados na construção do conhecimento profissional, com mais pertinência ao pensar sobre Enfermagem - seu saber e sua história. E no que me cabe reiterar, a postura pessoal.

Nesse sentido, e no que convém ao pensar sobre o assunto, percebo que a situação da pesquisa na Enfermagem, tem vantagens e percalços, e tenho aprendido que as condições do trabalho acadêmico, na estrutura universitária, implicam regras que influenciam a escolha de um tema, limitam a opção de problemas na pesquisa, e dificultam a perspectiva consistente com a atividade de pesquisar e, portanto, com a construção científica.

Os pesquisadores de enfermagem a custo conseguem contornar dificuldades ou limitações na trama de exigências que pesam sobre o conhecimento da própria área do saberfazer as coisas de sua prática. Assim, minhas posições visam a idéia representada pela questão de construir conhecimentos a meio caminho entre subjetividade e objetividade - aspectos epistemológicos destacados na construção desses conhecimentos, e como sucedem no plano do campo epistêmico.

Mas, falo de "subjetividade" no sentido de enfoque pendente à volição do sujeito (pesquisador) e a seu pensar em relação aos objetos da temática / problemática "Enfermagem e História da Enfermagem"; e trato da "objetividade" não somente enquanto referência a algo distinto do sujeito (objeto de estudo ou conhecimento produzido), mas principalmente, em referência a problemas cuja solução e interpretação dependem, também, de elementos existentes na envoltura histórica, contingente e subjetiva do assunto em estudo. Pode ser uma preferência filosófica, mas bem adequada ao saber profissional na Enfermagem, um saber específico que se manifesta, plenamente, na totalidade de um conjunto que se compõe com elementos da ordem de uma prática social e, ao mesmo tempo, com a determinação histórica da ordem propriamente intelectual e teórica.

Nesse particular - no que tange aos aspectos epistemológicos assim entendidos, diante dos objetivos de qualquer questão a investigar, cabe-me afirmar, em primeiro lugar, que o fundamental é ter consciência do real sentido da Enfermagem no mundo. Um sentido da "objetividade" que se manifesta pela historicidade dos fenômenos visados sob o espectro do espaço (de pesquisar), no nível das relações essenciais que sustentam tanto o espaço, quanto os fenômenos. Em particular, os objetos de estudo nos territórios de "Enfermagem e História da Enfermagem", embora pareçam cravados separadamente em tempo mais distante, podem ser representados, sob nossas vistas (de pesquisadores), como "0 conjunto das manifestações da atividade e do pensamento humanos, considerados em sua sucessão, seu desenvolvimento e suas relações de conexão ou dependência" e, assim, como se pertencente ao mundo de hoje ou de amanhã.

Com isto, os fatos ou fenômenos ganham mais sentido quando compreendidos em sua "historicidade" (caráter de tudo aquilo que se explica na história e pela história). Os jovens estudantes pesquisadores podem se ver como habitantes do mesmo espaço sujeitos-correlatos dos mesmos fatos ou fenômenos, e podem colaborar na descoberta de soluções para os problemas contemporâneos, mediante o esclarecimento de sua gênese, ou de seu desenvolvimento, e ainda podem ser testemunhos para o futuro.

A partir dessa idéia e, em segundo lugar, é preciso considerar, na situação atual de nosso mundo de mudanças aceleradas, que "0 pesquisador (ou historiador) se introduz na história de seu tempo", e que os temas incluídos no conteúdo ou no contexto do saber profissional não podem escapar ao crivo de influência da "subjetividade", posto que ela se manifesta na interpretação dos fenômenos ou dos fatos e até, no levantamento de hipóteses".

Entretanto, a posição social da Enfermagem é ainda, bem delicada, ou pelos limites do agir profissional no campo das ciências da saúde, ou pelos próprios desafios de investigar e produzir conhecimentos para ampliar o espaço do saber profissional. Um espaço que, de fato, nos termos globalizados da sociedade deste século XXI (terceiro milênio da Era Cristã), condiz agora com os descompassos de uma ordem política e econômica a desequilibrar todos os canteiros da atividade humana. Nas ciências conhecidas, há um tecnologia sem fronteiras cujos produtos seguem o rastro de um ideal sem limites. Os sábios das ciências físicas e matemáticas, cada vez mais abismados face à visão de uma realidade fantástica, buscam respostas para resolver ou problemas cotidianos comezinhos ou para nos lançar, decisivamente, na direção das galáxias a procura de novos mundos potencialmente habitáveis.

Em suma, na sociedade globalizada, nas circunstâncias da vida prática, vive-se hoje a angústia da incerteza e o medo de 
uma violência sem limites. Os cientistas da natureza, anteriormente tão preocupados com o significado da vida, agora lutam pelo domínio do código genético e disputam objetivos de projetos cientificamente arquitetados para a reprodução (ou clonagem) dos seres vivos.

\section{ASPECTOS DISTINTIVOS DA POSIÇÃO PESSOAL}

A consciência intelectual me tornou curiosa desde muito cedo, e dedicada aos assuntos da profissão de enfermeira. Ainda nos anos de 1950, aprendi de Waleska Paixão que "os conhecimentos da enfermagem vêm junto com os de história e estão de envolta, ainda, com os assuntos médicos, sociais, religiosos, e tudo em meio à visão do contexto abrangente do mundo em que vivemos" 2. Em suas lições de História da Enfermagem, de Ética Profissional, nas aberturas de cerimoniais solenes do protocolo institucional, seguidamente constavam três proposições que assumi como premissas fundamentais para a compreensão conceitual do saber e do agir profissional na enfermagem. Elas são as seguintes:

\section{A Enfermagem é um saber especifico de cuidar e uma profissão da saúde desenvolvida em estreita relação com a história da humanidade, e será sempre útil à enfermeira uma revisão desta para a melhor compreensão daquela.}

A História da Enfermagem deve despertar na enfermeira, com base no saber profissional e no conhecimento de suas origens e evolução, [uma] melhor compreensão da posição e deveres que the cabem, e o maior entusiasmo pelo seu ideal.

O progresso manifesta-se com ritmo desigual na maioria dos setores da atividade humana, razão porque os avanços da enfermagem não correspondem rigorosamente às descobertas das ciências, mesmo se correlatas.

Nos anos de 1961/62, estando nos Estados Unidos em estudos de pós-graduação, aprendi de Irene Beland e de sua literatura aplicada ao ensino e ao diagnóstico de situações - problema na enfermagem assistencial, que "embora o ideal de servir seja embrionário na arte de cuidar, a ciência afinal é que define as coisas do pensar, do conhecer e do que - fazer na enfermagem"3. Desde então, e com o apoio da filosofia, tenho prestado atenção às proposições epistemológicas em relação a conhecimentos em construção.

Contudo, o que tenho aprendido sobre 0 assunto sucede mais pela necessidade de discutir e trocar idéias com colegas e alunos sobre questões fundamentais da Enfermagem - ciência e arte. Particularmente, em relação ao pensar, ao conhecer ou ao fazer - plano da pesquisa e da produção científica, percebo ser imperiosa a lucidez de consciência, nas atitudes intelectuais e condutas investigativas, para advogar em favor da gênese, da consolidação, do desenvolvimento e dos saltos evolutivos da Enfermagem no mundo e no Brasil. E, nesse aspecto, o pano de fundo é sempre a História da Enfermagem. As questões aliadas ao progresso científico e aos avanços da profissão são do conhecimento de todos os que se dedicam à pesquisa, e precisam ser efetivamente consideradas.

Entendo que as questões da enfermagem-arte ganham relevância própria e justificativa se devidamente inseridas no plano da história da profissão. Entretanto, em relação à enfermagem-ciência ainda precisamos dominar as dificuldades da construção científica, e isto nos invoca a enfrentar não apenas o desafio das evidências sobre a prática, mas, principalmente, 0 status de um conhecimento capaz de alcançar grau equivalente ao do conhecimento confiável ${ }^{4}$. Ou, em outras palavras, precisamos clarear as incertezas relativas às dificuldades na pesquisa de enfermagem, especialmente àquelas relacionadas à construção do conhecimento, o que tem tudo a ver com o saber profissional e sua situação no plano da história, no mundo e no Brasil.

Em termos de generalidades históricas, pode-se dizer que a Enfermagem - saber e história, completados mais de 145 anos e em momentos decisivos do movimento evolucionário, já definiu forma e materialidade (objeto formal e objeto material), no plano do "pensar - saber" e do "saber-fazer" e nos termos de um indiscutível sistema organizado / englobante / abrangente / contextual da concepção de modernidade de prática profissional mundialmente conhecida. Um saber específico que se fez, por si, através de "um modelo teórico verificável para a formação da identidade profissional e que estabeleceu, em si, uma dobra segmentar na história das enfermeiras, [ou uma ruptura epistemológica com o présaber típico de assistir aos enfermos e sadios necessitados de cuidados de enfermagem], na Inglaterra da era vitoriana"5.

Graças às aproximações de efeito teorizante de Florence Nightingale ${ }^{6,7 c}$, o saber da enfermagem desenvolveu-se e, atualmente, confere com acumulações de conhecimentos científicos, tão fundamentais aos princípios básicos dos atos de cuidar, quanto coerentes com os objetivos do modelo de formar enfermeiras(os) em nível de ensino superior. Um saber profissional tão carregado de regras pedagógicas e preceitos éticos, quanto caracteristicamente conformado a um estilo peculiar de pensar e exercer atividades no mundo do trabalho.

Ainda assim, não se pode negligenciar que a Enfermagem ainda pode ser entendida como "uma-ciência-em-vias-de-se-fazer" sem que isso implique para a mesma um sentido precário. Ao contrário, este é um desafio típico do ritmo do progresso que não se manifesta, igualmente, em todas as áreas. Um desafio correspondente ao "caráter efêmero da modernidade da ciência um caráter epistemológico da terminologia bachelardiana", que vale pelo ideal de tensão modernista próprio da história das ciências. Um caráter que requer da ciência, [quando esta é tomada como objeto de estudo e no que tange a sua atualidade como saber], que esta seja freqüentemente refeita ou reconsiderada"; porém, com a obrigação de esclarecer sua historicidade como saber e como conhecimento, em sua própria condição, ou contingência, de modernidade:

O historiador das ciências [ou da História da Enfermagem] para julgar bem o passado, deve conhecer o presente; ele deve aprender da melhor maneira possivel a ciência da qual ele se propõe a escrever a história. E é isto que a 
história das ciências [ou História da Enfermagem], quer se queira ou não, tem uma forte ligação com a atualidade da ciência. A consciência de modernidade e a consciência de historicidade são aqui rigorosamente proporcionais ${ }^{9}$.

Nesse particular, como em outras formas do conhecer, não pode haver maiores prejuízos se a Enfermagem estiver ainda classificada entre as ciências do impreciso ${ }^{8}$. Mas, é preciso ter lucidez, pois, "a partir das verdades que a ciência atual tornou mais claras e melhor coordenadas, 0 passado de verdade aparece mais claramente progressivo enquanto passado"11. 0 que requer dos sábios e pesquisadores, impreterivelmente, que a Enfermagem dê testemunho (pela pesquisa), de sua atualidade ao nível de sua história e, principalmente, como ciência de seu tempo.

\section{OS DOCUMENTOS HISTÓRICOS DA EEAN - ASPECTOS GERAIS DA PESQUISA}

No final dos anos de 1980, quando a pesquisa científica começava a dar resultados com as dissertações do Curso de Mestrado da Escola de Enfermagem Anna Nery (EEAN), fui procurada por pelas professoras e ex-Diretoras Cecília Pecego Coelho e Elvira De Felice Souza, preocupadas com o acervo de documentos históricos da instituição. Tivemos uma breve discussão centrada na importância e variedade dos documentos arquivados - escritos (correspondências, planos, relatórios, registros escolares, atas), iconográficos (fotografias, mapas, plantas), sonoros (filmes, fitas K7, discos, CDs), os quais, no cômputo geral, conferiam com instrumentos básicos imprescindíveis à construção do conhecimento da memória institucional e da história da profissão.

Fui informada das dificuldades de obter recursos e auxílio financeiro para a infra-estrutura, segundo um ideal antigo capaz de manter a ordem e 0 acesso de pessoal docente, discente e pesquisadores. E, em relação aos pleitos junto à Universidade Federal do Rio de Janeiro (UFRJ), soube que a EEAN fora informada da necessidade de um projeto de pesquisa. Essas Professoras então, solicitaram-me que aceitasse coordenar as atividades de uma nova ordenação e classificação do material arquivado, para superar os problemas de acesso e favorecer a realização de estudos e pesquisas.

A nova incumbência foi positiva para o projeto de pesquisa "O Quadro Documental da EEAN/UFRJ - documentos históricos 1922/1992"100, cadastrado em 1990 na UFRJ, e em 1992 no Conselho Nacional de Pesquisa e Desenvolvimento científico e Tecnológico (CNPq) para efeito de obter o desejado apoio e auxílio financeiro. Assim, pessoalmente, tive o ponto de partida para a condição de "pesquisadora de documentos históricos". No início, a participação de Cecília Pecego Coelho foi imprescindível. Porém, a parceria de Jussara Sauthier tem sido altamente produtiva, inestimável, mormente em relação à metodologia de lidar/tratar/classificar o material arquivado, de executar planos e atividades na orientação de estudantes bolsistas e estagiários, de propor requisitos para informatizar os dados, de transformar os resultados em produção sob forma de livros e outros meios de divulgação.
Pode-se afirmar, sem dúvidas, a relevância dos documentos históricos da EEAN como apoio bibliográfico e base de quadro de referência no interesse da Enfermagem Brasileira. Do ponto de vista epistemológico, vale destacar também o valor fenomenotécnico (o termo é de Gaston Bachelard ${ }^{11}$ ) indiscutível dos dados constantes dos livros publicados sobre Documentos Históricos da EEAN ${ }^{12-14}$, mormente se entendidos como fontes primárias para a pesquisa e a produção científica. Com a prática de pesquisar esses documentos, e graças a esforços individuais e coletivos, avançamos na construção do conhecimento e na "difusão de uma filosofia de preservar os documentos históricos da enfermagem de forma a conservar sua memória" ${ }^{15}$. Assim, pudemos expandir, posteriormente, essa experiência da EEAN quanto à idéia de tratar o material arquivístico da instituição, as fontes de dados correspondem a verdadeiros documentos - testemunhos do memorial da EEAN e de sua marca histórica na realidade brasileira.

Com pouco mais de dez anos dessa experiência exemplar, ganhamos sabedoria para ampliar as possibilidades dos pesquisadores da enfermagem (e outros) face às fontes de dados para a Enfermagem e, sobretudo, com relevância e justificativa para a História da Enfermagem. Por justa razão, os estudos de construção do conhecimento, especialmente no âmbito do Núcleo de Pesquisa em História da Enfermagem Brasileira (Nuphebras), e a partir dessas fontes existentes no Centro de Documentação (CEDOC-EEAN), são de relevância inegável.

Em verdade, as pesquisas já avançavam, tanto mais destacadas pelo clima intelectual surgido com a pós-graduação stricto sensu, mormente após a implantação do Curso de Doutorado. As dificuldades foram sendo contornadas, aos poucos, e em virtude de nova organização de acesso aos documentos, da adoção de novos conceitos teóricos de metodologia da pesquisa, de novas técnicas de arquivologia, de novos métodos para classificar e implantar novos tópicos e séries temáticas para dar outra feição ao material do CEDOC uma fruição do labor profícuo de professores pesquisadores e de estudantes (bolsistas de iniciação científica, alunos de mestrado e doutorado, e estagiários). Com efeito, houve progresso; contudo, muitas dificuldades ainda persistem.

A justo título, cabe referir que, no Brasil, todos os pesquisadores de enfermagem envolvidos com pesquisa e produção científica, sob controle de requisitos dos Ministérios de Educação (MEC) e de Ciência e Tecnologia (CNPq), sabem das dificuldades nomeadas como de área de conhecimento. Em vista de impressões e interpretações, às vezes nocivas ao sentido (mais pleno) da profissão, alguns consultores ad hoc questionam e até negam aos pesquisadores de enfermagem 0 direito de optar por suas linhas de estudo e de estabelecer os limites do espaço epistemológico de suas pesquisas.

Essas dificuldades atingem a identidade profissional e prejudicam a posição cabível aos pesquisadores de enfermagem na estrutura universitária ou institucional. Em conseqüência, o desafio da "construção do conhecimento" no interesse da profissão assume proporções indesejáveis, mormente quanto às pesquisas essencialmente históricas. Em sã consciência, isto não nos cabe aceitar sem polêmica, afinal como profissionais 
de enfermagem, temos o direito - pro veritas - de dizer quem somos, o que podemos fazer, o que nos cabe pesquisar.

Com efeito, a dificuldade mais incômoda é, portanto, essencialmente de política acadêmica - a de falta de reconhecimento de que os próprios profissionais da enfermagem podem e devem pesquisar a historia de sua profissão. Uma boa parte de consultores ad hoc afirma que "a história é assunto do ofício de historiador"16. Daí que, na situação da EEAN, as disputas universitárias para se conseguir auxilio financeiro e apoio para a participação de bolsistas estudantes têm sido dramáticas.

Também, pode-se admitir que esta é uma dificuldade de delimitação epistemológica aliada a um certo equívoco sobre o que seja o saber espećífico da enfermagem, com implicações de demérito para o valor e a justificativa das pesquisas de história da profissão. Além de que, no campo próprio do conhecimento campo epistêmico, a Enfermagem como saber profissional, ainda sofre pressões intrínsecas e extrínsecas para se demonstrar com a intencionalidade objetiva (conhecimento objetivo?) no plano da prática de pesquisar e produzir conhecimento.

Mas essa não é uma questão exclusiva da EEAN. Na Enfermagem brasileira ela é quase generalizada, e os pesquisadores padecem dos efeitos de duas tendências nocivas, pesando sobre linhas de pesquisa e prioridades profissionais. 0 ponto nevrálgico é a objetividade do conhecimento no plano do saber e da história. A primeira tendência é representativa dos que advogam, para a Enfermagem na área da saúde, a condição de serviço meramente técnico ou de trabalho assistencial de apoio a outros profissionais. E, presumindo minimizar os limites e possibilidades no campo epistêmico (campo da pesquisa e da construção científica), a segunda tendência é corrente entre os que pretendem aprisionar ou reduzir o saber da profissão a concepções de caráter pré-científico, ou tecnificante, sem considerar sua relevância própria quanto aos princípios e parâmetros do Sistema Nightingale de Enfermagem Moderna. De fato, não se pode negar que as proposições nightingaleanas, na trajetória histórico - evolutiva, transcenderam atos e operações de cuidar nos termos do trabalho assistencial.

No território intra - muros da UFRJ, a questão cresce por conta da limitação de recursos e apoio eficaz ao trabalho de pesquisar, mais notória na situação da EEAN, cujos pesquisadores ressentem-se de reserva de tratamento até na distribuição de "bolsistas de iniciação científica". No terreno extra - muros, as dificuldades agravam-se, pois além do desafio de estabelecer distinção entre conhecimento comum e conhecimento científico, os pesquisadores da Enfermagem são submetidos aos indicadores de qualidade das ciências (re)conhecidas e enfrentam sanções das agências de fomento e amparo à pesquisa. Desafios de conseqüências prejudiciais, ainda, às estratégias pedagógicas de alcançar, em nível de avaliação superior, indicativos de maior qualidade para os programas de graduação e pós-graduação. E, com isso, podese pensar que a Enfermagem, seja como saber historicamente dado ou como arte pedagógica consistente com a educação superior, sofre prejuízos em sua legítima sistemática de preparar profissionais com qualificação acadêmica para a pesquisa, principalmente capazes de perseguir, pela prática da pesquisa, a cientificidade como condição à ultrapassagem de fronteiras de acesso ao domínio do campo epistêmico e que seja eficaz ao definitivo alcance do estatuto epistemológico.

\section{ENFERMAGEM, SABER E HISTÓRIA - UMA PARTICULARIDADE EPISTEMOLÓGICA}

Em que pese a validez de determinações epistemológicas para a Enfermagem - seu saber e sua história, cabe registrar aqui que, no Brasil, a profissão de enfermagem é legalmente consolidada quanto ao exercício de sua prática desde 1931, pelo Decreto-lei No. 20.109/31, com revisões ajustando o foco da ação profissional, através de dois instrumentos legais mais recentes - Decreto n. ${ }^{0} 94.406$ / 87 e Lei n. ${ }^{0} 7.498$ / 96. E, desde a década de 1970, por força da última Reforma Universitária - Lei n. ${ }^{0} 5.540$ / 68, a Enfermagem foi incluída como uma das sub-áreas do campo das Ciências da Saúde nos termos do Plano Básico de Desenvolvimento Científico e Tecnológico (PBDCT) / Decreto n. ${ }^{0} 70.553 / 72^{17}$, o qual trata especialmente de Pesquisa Fundamental e Pós-Graduação ${ }^{\text {. }}$ Para efeito de inclusão no PBDCT, a Enfermagem teve sua descrição definidora efetuada a partir da concepção nightingaleana primaz, e foi literalmente documentada como parte do sistema educacional de pós-graduação do país para a formação de professores, pesquisadores e cientistas ${ }^{\text {e }}$.

Assim, como saber específico e conhecimento próprio historicamente justificado e estabelecido em linhas de pesquisa, a Enfermagem foi assegurada nos termos de sua modernidade. Um saber e conhecimento específico que serviu de base para a implantação, em 1922, do Serviço de Enfermeiras de Saúde Pública do Departamento Nacional de Saúde Pública (DNSP) e, em 1923, para a fundação da Escola de Enfermeiras na estrutura desse mesmo Departamento - atual EEAN / UFRJ. Os ajustes no modelo da formação profissional em nível de educação superior foram registrados sem prejuízos para a feição da Enfermagem brasileira conforme o modelo Parsons ${ }^{18 f}$, cujo perfil profissional é consistente com o estilo formal de "saber-fazer as coisas e investigar os fenômenos de interesse da profissão". Um saber agora, tanto mais ressaltado, na questão de apresentar perguntas sobre "a construção do conhecimento".

Mais do que antes, importa agora buscar, através da pesquisa e da análise crítica, as respostas e possíveis soluções para o saber profissional - não apenas para a prática assistencial, mas como implicado na "história da profissão". Mais precisamente pela prática da pesquisa, importa agora levantar perguntas e apresentar as questões do pensamento sobre o conhecer e 0 acontecer no plano do fazer - como ordem intelectual e teórica. Nesse particular, é que surge a necessidade de discutir - no interesse da construção do saber/conhecimento profissional, "a Enfermagem e sua história" a partir do sentido de uma particularidade epistemológica.

Quanto a esse aspecto - e como o meu conhecimento visa apenas uma contribuição, vale principalmente a posição pessoal e o ponto de vista. Contudo, parafraseando Canguilhem ${ }^{19}$, podese dizer que a realidade "Enfermagem" - seja como saber ou 
como história, corresponde, de um lado, a um conjunto de experiências e explicações teóricas ou contribuições intelectuais acerca da ação e do pensar no âmbito da profissão; e, nesse sentido, ela é científica. E, por outro lado, essa mesma realidade - em razão da concepção nightingaleana de uma nova prática de enfermagem ter transcendido atos e operações de cuidar nos termos assistenciais, é histórica, no mesmo conjunto, o qual pertence globalmente à memória da profissão. Assim, segundo asserções do autor/epistemólogo ${ }^{19}$ :

Não é, portanto, vão nos interrogarmos primeiramente sobre a idéia que têm da história das ciências - [em nosso caso História da Enfermagem] - aqueles que pretendem se interessar por ela a ponto de fazê-la. No que diz respeito a este fazer - [fazer história], é certo que muitas questões há muito tempo têm sido postas e continuam a sê-lo. Estas questões são aquelas do Quem? do Por que? do Como?. Mas ocorre que uma questão principal que deveria ser colocada e não o é quase nunca, é a questão De Que? De que a história das ciências - [no nosso caso a História da Enfermagem], é a história? Que esta questão não seja colocada se deve ao fato de se acreditar que sua resposta esteja dada na expressão mesma de história das ciências, ou história da ciência [em nosso caso História da Enfermagem].

As questões "do Por que? e do Como?" certamente não precisam de discussão, porque relativas aos requisitos acadêmicos, às exigências da pesquisa e do ensino de disciplinas de formação profissional (no caso Enfermagem e História da Enfermagem e outras aliadas ou ao campo profissional ou ao campo epistêmico) e, também, porque pertinentes ao domínio do "saber específico da profissão", tal como situado no espaço social e na estrutura universitária. Aliás, nenhum equívoco pode haver sobre a situação da Enfermagem entendida como prática social ou saber específico de uma profissão. Ou seja, numa proposição bem direta, e em cômputo do geral, pode-se afirmar que, em sua atualidade, a Enfermagem trata e pesquisa questões de cuidar e ensinar a cuidar de pessoas e grupos humanos em situações da área da saúde ${ }^{20}$.

Porém, a polêmica surge em relação à História da Enfermagem, posto que pesam dúvidas quanto à idéia dos atributos e competências cabíveis ou relativas aos que podem ensinar e pesquisar. Todavia, as razões que podem explicar ou advogar o ensino de História da Enfermagem na estrutura do saber profissional são históricas, acompanham a expansão e o movimento evolucionário da profissão no mundo e, portanto, "0 modelo teórico verificável para a formação da identidade profissional, devidamente assentado por Florence Nightingale" 5 .

Por outro lado, aqui no Brasil, interpretando-se a Enfermagem nos termos do PBDCT ${ }^{17}$, como projeto profissional paradigmático, de efetivos procedimentos técnicos, conceituais e lógicos, um projeto acadêmico documentado não somente na arte de cuidar e nos planos de preparar pessoal em nível de pós-graduação, mas como um projeto decisivamente direcionado à prática da pesquisa e já bastante eficaz na concepção construtivista dos conhecimentos no interesse da Enfermagem - seu saber e sua história, não dá mais para aceitar qualquer equívoco quanto à questão De quem?
Penso que não pode e não deve haver dúvidas de que os profissionais de enfermagem são qualificados não só para atuar nos campos de prática assistencial; eles, com efeito, são competentes para ampliar o escopo do saber da profissão pela prática do ensino e da construção de conhecimentos de Enfermagem e História da Enfermagem, sobretudo, pela "prática - da - pesquisa - pela - pesquisa". E isto, eles conseguem dominar facilmente, nas experiências acadêmicas e no cultivo das linhas de pesquisa.

Portanto, voltando à questão De que? (ou de que se trata na história das ciências?), penso que cabe então, apresentar uma particularidade epistemológica tal como a percebo na construção do conhecimento e no interesse da "Enfermagem saber e história". Mais do que nunca, vale o ponto de vista. Assim, antes de enfrentar a questão da construção do conhecimento, cabe considerar que a idéia substantiva capaz de estabelecer um passo marcante para o alcance do estatuto da cientificidade, em especial quando se diz desse estatuto ser ele o equivalente do conhecimento objetivo talvez seja relevar, para a Enfermagem, a causa de uma ciência em construção ${ }^{21}$. Na dimensão do espírito científico - nesse caso, também uma ciência que é histórica, porque se percebe como conhecimento do passado a iluminar o caminho do saber específico próprio da profissão de enfermagem em sua atualidade e em seus avanços rumo ao amanhã. Por conseguinte, uma ciência que consegue perceber o presente como uma luz para melhor compreender 0 passado e intuir, prospectivamente, o futuro próximo.

Isto, se é que se pode compreender "a enfermagem-arte" como saber / conhecimento profissional (saber de uma prática científica) ainda não tanto ambiciosa de sucessos conseqüentes a resultados radicais. Mas, decisivamente, "uma-ciência-emvias-de-se-fazer" e já capaz de romper com experiências casuais e de se aventurar no terreno das experiências sob controle; ou decidida a superar o desafio de hipóteses consistentes com 0 pensamento histórico. Isto, se é que "a enfermagem-ciência" assim entendida, deve ser tratada também no plano das pesquisas históricas, que nos permitam compreender que "fazer a história [no caso a História da Enfermagem] é considerar o espírito humano em experiência, (...) é fazer uma história experimental do espírito humano"19. E aí a questão radical: - De que se faz (ou de que trata) o saber da história - na História da Enfermagem?

Confesso que não havia pensado nessa questão assim tão diretamente. Na Epistemologia, porém, considera-se a questão através de duas possibilidades de tratar os assuntos centrais de uma ciência no plano da história da mesma ciência. E aqui, novamente, valem as asserções de Canguilhem ${ }^{19}$ :

- De um lado, mediante uma abordagem externalista, "podese fazer a história das ciências [ou História da Enfermagem] condicionando um certo número de acontecimentos - que se continua a chamar de científicos mais por tradição do que por análise crítica -por suas relações com interesses econômicos e sociais, com exigências e práticas técnicas, com ideologias religiosas ou políticas".

- Por outro lado, mediante uma abordagem internalista, "não existe história das ciências [ou História da Enfermagem] se não nos situamos [como 
pesquisadores] no interior mesmo da obra científica [teorias ou explicações do saber da enfermagem] para analisar as andanças (démarches) pelas quais ela busca satisfazer as normas específicas que permitem definila como ciência e não como técnica ou ideologia".

Segundo este mesmo autor / epistemológo ${ }^{19}$ :

é claro que uma e outra posição levam a assimilar o objeto da história das ciências ao objeto de uma ciência [no nosso caso, o objeto da História da Enfermagem assimilado ao objeto da ciência da Enfermagem]. (...) Consistente com as influências da filosofia marxista, o externalista vê a história das ciências [ou a História da Enfermagem] como uma explicação de um fenômeno da cultura pelo condicionamento do meio cultural global e, conseqüentemente, assimilam-na a uma sociologia naturalista das instituições, negligenciando inteiramente a interpretação de um discurso com pretensão de verdade.

$\mathrm{Na}$ perspectiva internalista - marcadamente sob as influências do idealismo, "o historiador [ou pesquisador de enfermagem] deve adotar, uma atitude teórica com relação àquilo que é retido como fato de teoria e, assim, utilizar hipóteses, paradigmas, da mesma forma que os próprios sábios".

Há muito que se discutir com relação às duas formas de se fazer a história no campo de interesse da Enfermagem saber e história. Confesso que ainda preciso aprender muito acerca desta questão. No entanto, por justa razão, penso que se pode creditar inteira confiabilidade quanto aos interesses dos pesquisadores do Nuphebras (Núcleo de Pesquisa em História da Enfermagem Brasileira). Eles, certamente estão tratando de fazer a História da Enfermagem mediante as duas abordagens aqui referidas.

\section{EM NOME DA ENFERMAGEM - SABER E HISTÓRIA}

No que me concerne e tal como penso, os professores / pesquisadores na Enfermagem precisam ainda, submeter seus objetos de estudo às regras de verificabilidade falseabilidade ${ }^{22}$ adequadas às respostas alcançadas na objetividade de pesquisas inerentes à profissão e a seu modo de pensar saber e saber-fazer as coisas no mundo do trabalho assistencial. Quanto aos objetos de estudo inerentes ao pretendido saber de história da Enfermagem não vejo como escapar da obrigação de se tentar a objetivação da subjetividade ${ }^{23}$, para superar os obstáculos epistemológicos da construção do saber / conhecimento produzido.

Para tanto, é preciso "situar os problemas tais como eles se apresentam ou se omitem, se resolvem ou desaparecem na prática efetiva dos cientistas"24 [ou dos pesquisadores]. E, para situar e formular os problemas torna-se indispensável a presença de certos conceitos [epistemológicos] influentes nos aspectos destacados na construção do conhecimento profissional, quer seja entendido com base em objetos de ciência ou de história. Isto, se é que se deseja discernir entre "conhecimento comum e conhecimento científico [interesse da enfermagem-ciência] ou se é que se deseja elucidar algumas teses particulares, sem ter a audácia de fazer com que elas se beneficiem de uma demonstração completa"24.

Certamente vão precisar submeter as formulações oriundas da própria subjetividade ao crivo do pensamento histórico, e de toda forma aos requisitos da crítica e de conjeturas e reflexões ${ }^{7}$. Em que pese a posição crítica formal e o ponto de vista apresentado relativamente ao todo e às partes constitutivas desta temática, ouso pensar que ainda temos muito caminho adiante ou uma travessia de uma certa inércia do próprio pensamento - obstáculo epistemológico ${ }^{11}$, e vontade de pesquisar face aos interesses da profissão de enfermagem. Uma inércia ou passividade de colocar o pensamento ousado em proveito da necessidade de superar as dificuldades implicadas na prática da pesquisa e da construção da Enfermagem - seu saber e sua história.

À conta do exposto, penso que as possíveis objeções devem ser consideradas para efeito de balizar a posição crítica aqui definida. Relativamente aos aspectos epistemológicos destacados na construção do conhecimento profissional e no interesse da Enfermagem - saber e história, penso que todo este assunto tem sua relevância própria já assegurada e se justifica pela imperiosa necessidade da prática da pesquisa em virtude das exigências que pesam sobre a produção científica como requisito principal da qualidade acadêmica. Contudo, tal como percebo, sem a epistemologia fica muito difícil discernir entre a História da Enfermagem, dita aquela dos conhecimentos superados, e aquela dos conhecimentos sancionados, quer dizer ainda atuais porque ativos.

A abordagem aos aspectos epistemológicos aqui focalizados, não tem a pretensão de um caráter finalístico. Aliás, "a história é ciência dos assuntos humanos, ciência do homem"16. E em se tratado do homem e dos assuntos humanos éa ciência em si e por si. Mas, precisamos imperiosamente encarar a expressividade dos pesquisadores de enfermagem (atitudes e condutas) como parte integrante da contingência histórica, na estrutura das instituições, e na própria cultura da profissão.

Além do mais, somente através da prática da construção científica e de uma prática crítica, devidamente fundamentada em pesquisas do saber/conhecimento específico, será possível ampliar os espaços no campo epistêmico para a história da profissão. Mas, é preciso compreender e dar a devida atenção aos aspectos epistemológicos aqui referidos. A bem da verdade, penso que todos os professores / pesquisadores estão preparados para atender aos objetivos da preparação de recursos humanos para a promoção / recuperação da saúde e para o trabalho assistencial nos mais variados cenários, quer sejam institucionalizados ou não.

Porém, em vista dos objetivos tendentes a impulsionar a pesquisa para a construção do saber profissional, é preciso considerar adequadamente, e com a devida pertinência, os aspectos epistemológicos destacados em relação a conhecimentos em construção. A partir dos conceitos relativos aos aspectos epistemológicos já assentados - aqui secundando Canguilhem ${ }^{19}$ e Bachelard ${ }^{9}$, penso que vale considerar que:

A história das ciências [em nosso caso, a História da Enfermagem] é, na atualidade, o esforço para pesquisar 
e fazer compreender em que medida as ações profissionais ou as atitudes intelectuais ou os métodos [e técnicas] antes utilizados foram, em sua época, um avanço ou uma superação; $e$, conseqüentemente, de que forma [teoria e prática], na perspectiva [histórica] do passado superado, continua a ser o passado de uma atividade [profissional] à qual é necessário conservar o nome de científica.

Gostaria de poder dar uma interpretação melhor à questão da construção do conhecimento e aos aspectos epistemológicos considerados. Tais como tratados, aqui, e em nome da Enfermagem - saber e história, penso que os aspectos epistemológicos destacados na construção do conhecimento, e no que concerne aos interesses profissionais, estão a invocar a necessidade de implementar, cada vez mais, estratégias e mecanismos de intencionalidade objetiva que possam, de fato,

\section{Referências}

1. Glénisson J. Iniciação aos estudos históricos. Colaboração de Campos PM, Costa EV. São Paulo (SP): Difusão Européia do Livro; 1961.

2. Paixão W. Páginas de história da enfermagem. $2^{\mathrm{a} e d}$. rev. Rio de Janeiro (RJ): Bruno Buccini; 1960.

3. Abdellah FG, et al. Patient-centered approaches to nursing. New York (USA): Macmillan; 1961.

4. Ziman J. 0 conhecimento confiável: uma exploração dos fundamentos para a crença na ciência. Campinas (SP): Papirus; 1996.

5. Miranda CML. 0 risco e o bordado: um estudo sobre formação de identidade profissional. Prefácio de Vilma de Carvalho. Rio de Janeiro (RJ): EEAN/UFRJ; 1996.

6. Nightingale F. Notas sobre enfermagem: o que é e o que não é. Tradução de Amália Corrêa de Carvalho. Prefácio de leda Barreira e Castro. São Paulo (SP): Cortez; 1989.

7. Carvalho V. Acerca de las bases teóricas, filosóficas, epistemológicas de la investigación científica: el caso de la enfermería. Rev Latino-am Enfermagem 2003 nov/dez; 11(6): 807-15.

8. Moles AA. As ciências do impreciso. Colaboração de Elisabeth Rohmer. Tradução de Glória de Carvalho Lins. Rio de Janeiro (RJ): Civilização Brasileira; 1995.

9. Bachelard G. Aatualidade da história das ciências. Tempo Bras: epistemologia 1972 jan/mar; 28: 22-26. Conferência no Palais de la Découverte; 1951.

10. Carvalho V, Coelho CP. 0 quadro documental da Escola de Enfermagem Anna Nery (UFRJ): documentos históricos - 1922/ 1992. Rio de Janeiro (RJ): ABEn; 1991.

11. Bachelard G. A formação do espírito científico: contribuição para uma psicanálise do conhecimento. Tradução de Estela dos Santos Abreu. Rio de Janeiro (RJ): Contraponto; 1996.

12. Sauthier J, Carvalho V. A Missão Parsons: documentos históricos da EEAN/UFRJ 1922/1931. Rio de Janeiro (RJ): EEAN/UFRJ; 1999. (História da Enfermagem Brasileira, 1). alimentar e enriquecer as possíveis abordagens para a questão colocada como "A Construção do Saber de História da Enfermagem".

0 tratamento dessa questão, segundo os termos da consciência intelectual de ser enfermeira e pesquisadora de documentos históricos, está somente calcado na ousadia de um ponto de vista, o qual acredito razoavelmente bem orientado para dar vida a uma posição crítica frente aos aspectos epistemológicos focalizados a meio caminho entre subjetividade e objetividade na construção do conhecimento profissional da enfermagem.

Eis aí, pois, os primeiros termos de minha contribuição. Mas ainda prefiro, e a despeito de todas as considerações efetuadas, deixar em pauta a minha perplexidade. E a pergunta que se impõe então é: De que se faz (ou de que trata) o saber da história - na História da Enfermagem? Acredito que é aí, e a partir de respostas - tentativas, que o saber da Enfermagem avança e a História da Enfermagem se desenvolve.

13. Carvalho V, Sauthier J. As pioneiras e a consolidação da enfermagem no Brasil: documentos históricos da EEAN/UFRJ 1932/1950. Rio de Janeiro (RJ): EEAN/UFRJ; 2004. (História da Enfermagem Brasileira, 2). Publicado também em CD-ROM.

14. Carvalho V, Sauthier J. Annaes de Enfermagem: informatização das publicações de 1932 a 1954. Rio de Janeiro (RJ): EEAN/UFRJ; 2002. (Compreende toda a coleção, o periódico é, atualmente, a Revista Brasileira de Enfermagem da Associação Brasileira de Enfermagem-ABEn).

15. Sauthier J. A preservação de fontes para pesquisa. Anais do $2^{\circ}$ Fórum Mineiro de Enfermagem "Pesquisar para Caminhar" 2000; Uberlândia (MG), Brasil. Uberlândia (MG): UFU; 2000.

16. Bloch M. Apologia da história ou o ofício de historiador. Edição anotada por Étienne Bloch. Tradução de André Telles. Rio de Janeiro (R):Zahar; 2001.

17. Presidência da República. Secretaria de Planejamento. Plano Básico de Desenvolvimento Científico e Tecnológico-PBDCT: pesquisa fundamental e pós-graduação/ Ciências da Saúde. Brasília (DF); 1974.

18. Parsons E. A enfermagem moderna no Brasil. Esc Anna Nery Rev Enferm 1997 jul; 1 ( $n^{0}$ esp lanç): 9-24.

19. Canguilhem G. 0 objeto da história das ciências. Tempo Bras: epistemologia 1972 jan/março; 28: 7-21; 1966.(Conferência realizada em Montreal)

20. Carvalho V. A enfermagem de saúde publica como prática social: um ponto de vista crítico sobre a formação da enfermeira em nível de graduação. Esc Anna Nery Rev Enferm 1997 jul; (nesp lanç): 25-41.

21. Carvalho V, et al. Questões epistemológicas da construção do conhecimento na enfermagem: do ensino à prática de cuidar. Esc Anna Nery Rev Enferm 2003 ago; 7(2): 156-66. (Apresentado no $12^{\circ}$ Seminário Nacional de Pesquisa em Enfermagem; Porto Seguro (BA); maio 2003).

22. Demo P. Teoria: porque? Anais do $1^{\circ}$ Simpósio Brasileiro de Teorias de Enfermagem; 1985 maio; Florianópolis (SC), Brasil. Florianópolis (SC): Ed da UFSC; 1985.

23. Japiassu H. Introdução ao pensamento epistemológico. $2^{\mathrm{a}}$ ed. Rio de Janeiro (RJ): Francisco Alves; 1977.

24. Popper KR. Conhecimento objetivo. Belo Horizonte (MG): Itatiai ; 1975. 


\section{Notas}

${ }^{a}$ Trabalho originalmente apresentado no II Colóquio Latino-Americano de História da Enfermagem; 2005 set 12 - 15; Rio de Janeiro (RJ), EEAN/ UFRJ, como conferência realizada no dia 13 de setembro de 2005.

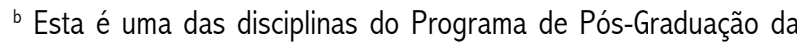
EEAN, implantada no Curso de Doutorado em 1989, e até agora sob a responsabilidade da autora. Sua ementa tem o seguinte conteúdo: Trata da Enfermagem como saber / conhecimento, da construção científica e conceitos influentes na formação da mentalidade científica, e de implicações na produção do conhecimento profissional.

c Artigo originalmente proferido como conferência no âmbito da Conferencia en el Curso / Encuentro Internacional de Investigación en Salud. Un programa científico del Colégio Nacional de Enfermeros del Perú. Ciudad de Lima (PE), Jun 2001.

¿ $O$ plano básico do PBDCT foi coordenado por Coura JR.

e 0 trabalho relativo à parte da Enfermagem foi elaborado sob a coordenação da Prof ${ }^{a}$ Dr ${ }^{a}$ Elvira De Felice Souza, à época Representante da área de Enfermagem.
† Além dos aspectos da Enfermagem Brasileira, Parsons trata das características do perfil profissional da Enfermeira de Saúde Pública e do modelo de formação de enfermeiras implantado no Brasil sob sua liderança, como enfermeira norte-americana, Chefe da Missão Técnica de Cooperação para o Desenvolvimento da Enfermagem no Brasil - atualmente denominada Missão Parsons; historicamente sucedida de 1922 a 1931.0 artigo original tem sua versão em inglês publicada no American Journal of Nursing, v. 26, June 1927; e, em português publicada nos Archivos de Hygiene - Exposições e Relatórios - DNSP, 1928; existe ainda uma outra cópia no CEDOC / EEAN, com texto em fac-símile, Módulo A, Caixa 01, Documento 16.

\section{Sobre a Autora}

\section{Vilma de Carvalho}

Professora Emérita / UFRJ. Bacharel e Licenciada em Filosofia / UERJ. Pesquisadora CNPq. Coordenadora / Líder do Grupo da Linha de Pesquisa e Estudos Epistemológicos para a Enfermagem (Lepisteme) registrado na UFRJ e no CNPq. Docente do quadro permanente dos Cursos de Pós-Graduação da EEAN /UFRJ. 